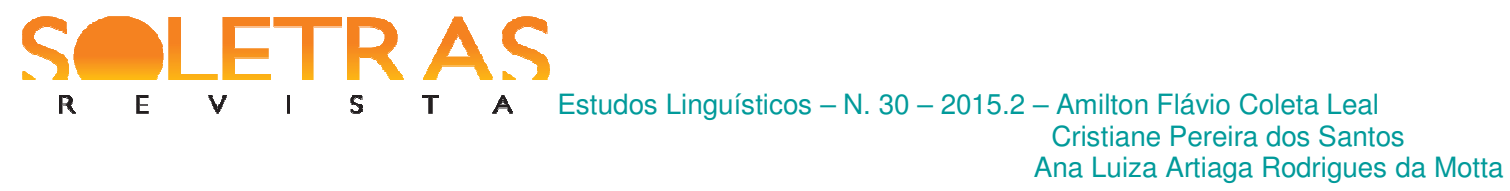

\title{
A reformulação das portarias do ENEM: uma análise discursiva das diferentes versões ${ }^{1}$
}

\author{
Amilton Flávio Coleta Leal ${ }^{2}$ \\ Doutorando em Linguística pela UNEMAT \\ Cristiane Pereira dos Santos $^{3}$ \\ Mestra em Linguística pela UNEMAT \\ Ana Luiza Artiaga Rodrigues da Motta ${ }^{4}$ \\ Universidade do Estado do Mato Grosso (UNEMAT)
}

\begin{abstract}
Resumo: Neste trabalho, o tema linguagem e sentido é trabalhado na perspectiva da Análise de Discurso, fundada nos trabalhos de Michel Pêcheux, na França e Eni Orlandi, no Brasil. Objetivamos refletir o processo de instituição jurídica do ENEM, a política avaliativa do Exame e uma análise das reformulações das três principais portarias, desde que fora instituído, em 1998, até 2012. Destacamos a relevância deste estudo para o domínio da linguagem, sobretudo, para os pesquisadores que se voltam a pensar sobre as políticas educacionais, uma vez que a política avaliativa do Exame Nacional constitui-se como o instrumento avaliador e quantificador das competências dos candidatos que, por sua vez, direcionam as políticas de Estado em relação ao cenário escolar. Dessa forma, dizemos que refletir sobre a política nacional de avaliação do ENEM, nos fez pensar numa questão muito 'cara' ao ensino no Brasil: a relação sujeito/escrita.
\end{abstract}

Palavras-chave: Análise de Discurso. ENEM. Portarias.

\section{Introdução}

O Exame Nacional do Ensino Médio, a cada edição, vem conquistando maior espaço nas políticas de avaliação do país. A repercussão e legitimidade da prova ocorreram ao longo das sucessivas edições e, atualmente, ocupa a centralidade das discussões no cenário educacional, seja do ensino médio e/ou da educação superior. Neste trabalho, propomos refletir, de maneira geral, a política de avaliação do ENEM e, de maneira particular, analisar

\footnotetext{
${ }^{1}$ Recorte da Dissertação de Mestrado (Leal, 2015).

${ }^{2}$ Graduado em Letras pela Universidade do Estado de Mato Grosso (UNEMAT) e Mestre em Linguística pela mesma instituição. Atua como professor da Rede Estadual de Ensino. Atualmente é Doutorando em Linguística, também, pela UNEMAT. E-mail: amiltonflavio@ hotmail.com.

${ }^{3}$ Graduada em Letras pela Universidade do Estado de Mato Grosso (UNEMAT) e Mestra em Linguística pela mesma instituição. Atua como professora da Rede Estadual de Ensino. E-mail: cris_tanynha@ hotmail.com.

${ }^{4}$ Doutora em Linguística pela Universidade de Campinas (UNICAMP). É professora do Departamento de Letras, do Mestrado e do Doutorado em Linguística da Universidade do Estado de Mato Grosso. E-mail: analuizart@unemat.br.
} 


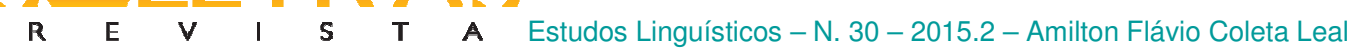 \\ Cristiane Pereira dos Santos \\ Ana Luiza Artiaga Rodrigues da Motta}

discursivamente a reformulação das portarias, isto é, ao longo das sucessivas edições, o Exame Nacional passou por modificações, desde sua instituição, pela Portaria INEP $n^{\circ} 438$, de 28 de maio de 1998, até suas reformulações: Portaria INEP n 109, de 27 de maio de 2009 e Portaria INEP $n^{\circ}$ 144, de 24 de maio de 2012. São estas portarias, as quais recortamos para análise, que funcionarão como objeto de análise e nos permitirão discorrer sobre as questões referentes ao ensino no país, via ENEM.

Ao tomarmos o ENEM como objeto de pesquisa, estamos comprometidos com um fato de linguagem que nos dá pistas da "severa" disputa do acesso ao Ensino Superior, pois o processo avaliativo do ENEM provoca efeitos de sentido nas discussões sobre o ensino no país, que diz respeito sobre a forma como são selecionados os candidatos para o Ensino Superior, o que produz gestos de interpretação que repercutem na maneira como está "posto" a distribuição de vagas nas universidades públicas e/ou privadas. Dessa forma, ao considerarmos o ENEM como uma avaliação em larga escala, assim como a reformulação das portarias, há que se pensar que os sujeitos-participantes estão inscritos nas mais diversas condições de produção, o que produz como efeito da avaliação, a aprovação de uns e a exclusão de muitos.

Assim, ao tomarmos a política nacional de avaliação do ENEM, nos inscrevemos em um lugar teórico-analítico para refletirmos sobre uma questão muito 'cara' ao ensino no Brasil: a relação sujeito/escrita. Dessa forma, o que refletiremos, no presente artigo, diz respeito a um Exame que deriva de uma política do $\mathrm{INEP}^{5}$, legitimada por um discurso pedagógico que diz sobre o processo avaliativo do aluno ao final do ensino médio, o qual passou a funcionar, ao longo das edições, como uma política avaliativa que possibilita o acesso ao ensino superior.

\section{Breve histórico do ENEM}

Primeiramente, pensemos as relações institucionais entre MEC-INEP-ENEM. Ao INEP, cabe oferecer dados referentes à educação brasileira, já que essa instituição reguladora funciona como a responsável pelo processo avaliativo da posição sujeito-aluno, uma forma

\footnotetext{
${ }^{5}$ Instituto Nacional de Pesquisa e Estatística Anísio Teixeira. O INEP é um órgão ligado ao próprio MEC. Surgiu em 1984 e funciona como um sistema de informações, pesquisas e estatísticas na publicação dos resultados de avaliação de todas as etapas de ensino. Disponível em www.inep.gov.br. Acessado em: 16 de maio de 2014.
} 


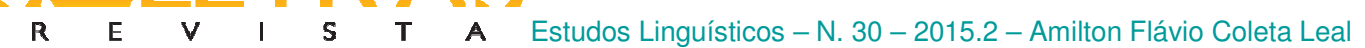 \\ Cristiane Pereira dos Santos \\ Ana Luiza Artiaga Rodrigues da Motta}

determinante no modo de individuação da forma-sujeito histórica ${ }^{6}$. Em outros termos, o INEP, porta-voz oficial do Estado (SIMÕES, 2014), é o órgão que responde e faz publicizar o resultado estatístico do Exame Nacional.

Em 1998, o ENEM, em sua primeira edição, contou com um número de 157,2 mil inscritos. Após três anos, em sua quarta edição, alcança um número expressivo de 1,6 milhão de inscritos. De acordo com o INEP a expansão no número de participantes deve-se, em primeira instância, à isenção do pagamento da taxa de inscrição para os alunos de escola pública, à aceitação e ao apoio das Secretarias Estaduais de Educação, das escolas de ensino médio e das Instituições de Ensino Superior (IES), que corroboraram, igualmente, para o crescimento e repercussão do Exame.

Pode-se dizer que a popularização do ENEM ocorreu em 2004, quando o Ministério da Educação $\left(\mathrm{MEC}^{7}\right)$ instituiu o Programa Universidade para Todos, ProUni ${ }^{8}$, que tem uma política de bolsas de estudos a alunos de todo o país, em IES, a partir da nota obtida no Exame. Em 2005, o ENEM já alcançava a marca histórica de três milhões de inscritos e, em 2006, contou com 3,7 milhões de participantes. Nas últimas edições (2013-2014), o Exame, mais uma vez, estabeleceu novos recordes de inscritos. Em 2013, contabilizou-se mais de sete milhões e em sua $16^{\text {a }}$ edição (2014), o Exame ultrapassou os 9,5 milhões de inscritos.

Os registros numéricos dão visibilidade à maneira como se deu o crescimento e repercussão do ENEM, bem como a aceitação de Universidades do país, em utilizar a prova como forma de seleção de candidatos ao ensino superior. Compreendemos que a possibilidade de acesso à universidade pelo ProUni e pelo SISU $^{9}$, são ações que significam, também, a legitimação aos candidatos para inscreverem para a prova.

Pensar o processo avaliativo do ENEM nos conduz a refletir sobre o EstadoAvaliador $^{10}$ (ALVES, 2009), como lugar em que as políticas educacionais assumem

\footnotetext{
${ }^{6}$ A forma-sujeito, conforme Orlandi (2010), está inscrita na concepção de um sujeito ao mesmo tempo livre e submisso às regras, às limitações do Estado. Assim, observa-se que a posição sujeito-aluno versus escrita é uma relação em que se pode observar um lugar de coerções, uma vez que a língua é o lugar da regularidade.

${ }^{7}$ Ministério da Educação e Cultura.

${ }^{8}$ O Programa Universidade para Todos (ProUni) foi criado em 2004, pela Lei $\mathrm{n}^{\circ} 11.096 / 2005$, e tem como finalidade a concessão de bolsas de estudos integrais e parciais a estudantes de cursos de graduação e de cursos sequenciais de formação específica, em instituições privadas de educação superior. O PROUNI foi instituído pela medida provisória n $\mathbf{n}^{\mathbf{2}} \mathbf{2 1 3}$, de 10 de setembro de 2004, convertida na Lei no 11.096, de 2005.

${ }^{9}$ Instituído pela portaria normativa $\mathrm{n}^{\mathbf{0}} 2$, de 26 de janeiro 2010. Institui e regulamenta o Sistema de Seleção Unificada, sistema informatizado gerenciado pelo Ministério da Educação, para seleção de candidatos a vagas em cursos de graduação disponibilizadas pelas instituições públicas de educação superior dele participantes.

${ }^{10}$ Ao falar de Estado-Avaliador, Alves (2009) traz Sobrinho (2003, p.59) que diz: "como avaliador ou interventor, o Estado costuma praticar uma avaliação predominantemente controladora e organizadora de suas
} 
estratégias na busca pela melhoria e eficiência na qualidade da educação. $O$ 'EstadoAvaliador' assume funções prioritárias de legislar e avaliar, pois ao organizar e realizar o ENEM textualiza-se, também, o processo educacional a partir das políticas públicas que, por sua vez, fixam e definem os processos de avaliação, dando visibilidade às questões referentes ao ensino no país pelos resultados desses processos.

O INEP, pelo processo de seleção do ENEM, funciona como um método que institui o acesso à Universidade. O Exame deixa de ser conhecido pelo caráter, eminentemente, avaliativo do ensino médio e passa a funcionar como referência de processo seletivo para ingresso no ensino superior, garantindo a ele o status de modelo avaliativo. Nessa linhagem, a política nacional do ENEM configura um apontamento para o ensino médio, uma vez que o acesso ao ensino superior depende da base constitutiva desta etapa de ensino.

\section{Da instituição às mudanças no Exame Nacional: a reformulação das portarias}

O Exame Nacional passou, ao longo de suas edições, por três fases. Conforme Santos (2011), a primeira refere-se ao período de 1998 a 2003, em que o caráter do Exame era, fundamentalmente, avaliar o ensino médio brasileiro e a possibilidade de acesso ao ensino superior era restrita a algumas instituições federais. A segunda fase inicia-se em 2004 quando o Exame passa a funcionar como instrumento seletivo e o Estado passa a conceder bolsas parciais e integrais em IES privadas, através do ProUni. A última fase ocorre a partir da edição de 2009, quando o INEP promove mudanças nos objetivos e na própria estrutura organizacional das provas.

Assim, desde 1998, o Exame, aplicado em um único dia, compunha-se de sessenta e três questões objetivas e uma discursiva (redação), em que o participante dispunha de cinco horas para a realização da prova. Com a Portaria $n^{\circ}$ 109/2009, a prova passa a ser aplicada em dois dias e divide-se em quatro áreas do conhecimento. Diante das condições de organização das áreas, o candidato passa a ter, no primeiro dia, noventa questões objetivas referentes às áreas de Ciências Humanas e Ciências da Natureza, em um tempo de quatro horas e meia. Já no segundo dia, o candidato tem noventa questões objetivas das áreas de Linguagens Códigos e suas Tecnologias e Matemática, e uma redação, num tempo limite de cinco horas e meia.

políticas de distribuição de recursos. Em geral, são avaliações externas, somativas, orientadas para o exame dos resultados, e seguem prioritariamente os paradigmas objetivistas e quantitativistas”. 
De acordo com Simões (2013), o ENEM não pode ser entendido unicamente como uma somatória de questões objetivas e uma redação, mas como um recorte discursivo. Para isso, é necessário pensar as condições de produção do Exame. Dessa forma, essas mudanças organizacionais na prova nos oferecem lugares de interpretação; de pensar os efeitos de sentido que essas ações demandam. Assim, o INEP, ao instituir tais alterações, produz um efeito de amplitude, que repercute no aumento de inscritos, sobretudo, na especificidade de avaliação; como possibilidade de acesso ao ensino superior.

O ENEM, instituído pelo MEC/INEP, Portaria INEP n ${ }^{\circ} 438$, de 28 de maio de $1998^{11}$, vem, desde 2009, com a reformulação "Novo Enem" (Portaria $\mathrm{n}^{\circ}$ 109, de 27 de maio de 2009), discutindo a posição política no processo seletivo de alunos para as IES no país. Da instituição do ENEM, afirma-se:

Artigo $1^{\circ}$ - Instituir o Exame Nacional do Ensino Médio - ENEM, como procedimento de avaliação do desempenho do aluno, tendo por objetivos:

I - conferir ao cidadão parâmetro para auto avaliação, com vistas à continuidade de sua formação e à sua inserção no mercado de trabalho;

II - criar referência nacional para os egressos de qualquer das modalidades do ensino médio;

III - fornecer subsídios às diferentes modalidades de acesso à Educação superior. (Portaria MEC nº 438, de 28 de maio de 1998).

Observa-se (no art. $1^{\circ}$, incisos I e II), que a política de instituição do Exame configura, por um lado, um parâmetro de autoavaliação do candidato, sua inserção no mercado de trabalho e, por outro, a possibilidade de acesso ao ensino superior. Do ponto de vista de Pfeiffer (2011), o discurso das políticas públicas aponta para o lugar da inclusão, do acesso. Barbosa (2013) afirma que o discurso do Exame Nacional, como política pública, funciona como o discurso do Estado, que institui, imaginariamente, o acesso para todos, inscrevendo-se no discurso da democratização do acesso ao ensino superior. Assim, do ponto de vista discursivo, a palavra acesso pode ter múltiplos sentidos. Conforme Pêcheux (1975), a palavra não tem o sentido na literalidade, mas nas diferentes formações discursivas; estas compreendidas como o que pode e o que não pode ser dito (PÊCHEUX, 2009).

Dessa forma, o termo acesso, no discurso da Portaria no 438/1998 inscreve-se em uma formação discursiva que remete a sentidos possíveis: acesso (permitido, controlado) e acesso (restrito, como mecanismo de exclusão). Chamamos a atenção para o sentido de acesso

${ }^{11}$ A Portaria que institui o ENEM é um cumprimento que atende ao dispositivo jurídico da LDB - Lei de Diretrizes e Bases (1996), que determina em seu artigo $9^{\circ}$, inciso VI, que seja organizado um processo de avaliação do rendimento escolar em âmbito nacional, com o objetivo de definir prioridades e a melhoria da qualidade do ensino no país (BARBOSA, 2013, p. 21). 
(regulado) em vez de acesso (passagem, livre), pois, trata-se de um Exame que avalia alunos que concorrerão vagas no ensino superior, embora inscrito numa política dita democrática.

Pode-se dizer que o termo acesso, inscrito no inciso III da Portaria $n^{\circ} 438 / 1998$, desliza para sentidos de controle, uma vez que ingressar no ensino superior, tendo como critério a nota do ENEM, é uma questão limitada. E ainda, o termo acesso funciona como um mecanismo de exclusão, de segregação. O processo de instituição do ENEM, no que tange à avaliação, reverbera sentidos sobre competências e habilidades que o sujeito-aluno precisa demonstrar ao final do ensino médio. Isso produz gestos de leitura sobre o discurso do INEP em relação ao aluno concluinte do ensino médio e à inserção no mercado de trabalho. Chamanos a atenção ao fato de formação e mercado de trabalho aparecerem empregados de maneira coordenada. Trata-se de um modo de o ENEM se definir; como procedimento de avaliação de desempenho do aluno, que o configura como aquele que avalia para o acesso à universidade e que é capaz, ainda, de dizer sobre o nível de desempenho da posição-sujeito para o mercado de trabalho.

Os objetivos I e II da Portaria 438/1998 dizem, ainda, sobre o processo de instituição do ENEM como uma prova que objetiva conferir ao cidadão parâmetro para autoavaliação. Essa proposição do Exame produz efeitos de sentido que legitimam e/ou positivam a prova em relação ao sujeito-aluno, suas escolhas futuras e ao mundo do trabalho, isto é, o Exame, além de avaliar alunos do ensino médio, corrobora como referência à continuidade no mundo profissional. $\mathrm{O}$ aluno submete-se ao Exame para se autoavaliar, tanto em relação à formação (processo de escolarização) quanto à inserção no mercado de trabalho. Isso nos mostra um discurso que diz sobre a posição sujeito-aluno em relação à sua competência em resolver e/ou atualizar problemas sociais; um discurso atual, do acesso ao mercado de trabalho.

Nesse sentido, a política do ENEM interfere nesses dois âmbitos: formação e mercado de trabalho. O Exame se define também, pela política de Estado, como referência nacional para os egressos de qualquer das modalidades do ensino médio (Portaria INEP). E esta é mais uma maneira de enunciar seu caráter regulatório e legitimador, uma modalidade de acesso que aponta para a expansão de seu domínio.

Em 2009, institui-se uma nova Portaria (109/2009), que se fundamenta nos seguintes objetivos:

Art. $2^{\circ}$ Constituem objetivos do Novo Enem:

I - oferecer uma referência para que cada cidadão possa proceder à sua autoavaliação, com vistas às suas escolhas futuras, tanto em relação ao mundo do trabalho quanto em relação à continuidade nos estudos; 
II $-(\ldots)$;

Estudos Linguísticos - N. 30 - 2015.2 - Amilton Flávio Coleta Leal

Cristiane Pereira dos Santos

Ana Luiza Artiaga Rodrigues da Motta

III - estruturar uma avaliação ao final da educação básica que sirva como modalidade alternativa ou complementar aos exames de acesso aos cursos profissionalizantes, pós-médios e à Educação Superior (Portaria INEP $\mathrm{n}^{\circ}$ 109, de 27 de maio de 2009).

Como se pode observar, a referida Portaria traz alterações no ENEM, que passam a funcionar como uma nova versão, conhecida como Novo Enem. Após 2009, a prova amplia significativamente a possibilidade de acesso ao ensino superior, pelos programas SISU, ProUni e FIES ${ }^{12}$, o que provoca um deslocamento na maneira de se adentrar à Universidade, via ENEM.

Primeiramente, pensamos nos efeitos de sentido produzidos pela (re) denominação ${ }^{13}$ Novo ENEM. Orlandi (2008) diz que toda denominação acarreta um silêncio ${ }^{14}$ que o fato de nomear produz. A denominação Novo Enem projeta-se como novo, em que a adjetivação "novo" se circunscreve, imaginariamente, em outra proposição política de Estado, porém a formulação dos incisos I e III da portaria 109/2009, no que tange ao acesso ao ensino superior e ao mercado trabalho, não se rompem, mas se repetem. Assim, observa-se que, entre as portarias 438 e 109 não há mudanças nos objetivos, mas há um alargamento dos mecanismos de acesso, pelos programas seletivos de acesso ao ensino superior.

Entendemos, dessa forma, que a designação Novo Enem mantém uma prática discursivo-ideológica em que, no final do ensino médio, o sujeito-aluno, obrigatoriamente, para ultrapassar os saberes nomeados por 'médios' e alcançar o status de superior, deve-se mostrar competente na avaliação proposta (SIMÕES, 2014). O que muda é a modalidade alternativa ou complementar aos exames de acesso aos cursos profissionalizantes, pós-médios e à Educação Superior (Portaria INEP).

Assim, a partir da denominação Novo ENEM, o INEP propõe uma referência para que cada cidadão possa proceder à sua autoavaliação, com vistas às suas escolhas futuras, tanto em relação ao mundo do trabalho quanto em relação à continuidade nos estudos. Isso agrega sentidos outros ao Exame e aponta para a ressignificação do Ensino Médio, o que dá visibilidade à legitimação do ENEM em relação ao segundo grau.

\footnotetext{
${ }^{12} \mathrm{O}$ Fundo de Financiamento ao Estudante do Ensino Superior (FIES) é destinado à concessão de financiamento a estudantes regularmente matriculados em cursos superiores não gratuitos e com avaliação positiva nos processos conduzidos pelo Ministério da Educação e está regulamentado pela Portaria Normativa $\mathrm{n}^{\mathrm{o}} 1$, de 22 de janeiro de 2010 .

${ }^{13}$ Uma análise a respeito do Discurso da Nova República, proferido por Tancredo Neves em seu discurso de vitória, encontra-se em Orlandi (2008).

14 "O silêncio não é transparente. Ele tem sua espessura e instaura processos significativos complexos" (ORLANDI, 2008, p.42).
} 
Nota-se que a portaria $n^{\circ}$ 109/2009 enuncia de outro modo sobre formação e mercado de trabalho. Diferentemente da Portaria n 438/1998, a segunda portaria diz que o ENEM se define enquanto referência para as escolhas futuras, tanto em relação ao mundo do trabalho quanto em relação à continuidade de estudos, ocorrendo um deslizamento de sentidos. Pela formulação, observa-se que o ENEM, enquanto política de Estado, não só regula o acesso para o ensino superior, mas propõe legitimar a inserção do aluno em outros âmbitos, o que configura maior amplitude do Exame. Assim, o Exame passa a funcionar como "modelo de avaliação" de uma macro política de democratização e consenso que, juntas, legitimam o ENEM como uma política de acesso à Universidade.

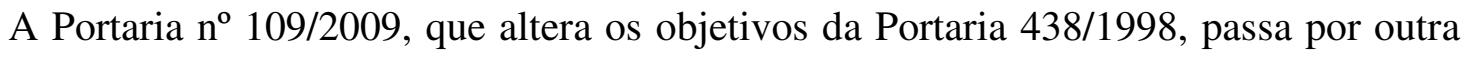
reformulação, pondo em circulação a Portaria INEP no 144, de 24 de maio de 2012. Tal portaria diz, entre outras coisas, sobre a possibilidade de certificação do Ensino Médio a partir da nota do ENEM:

Art. $1^{\circ}$ A certificação de conclusão do ensino médio e a declaração parcial de proficiência com base no Exame Nacional de Ensino Médio (ENEM) destinam-se aos maiores de 18 (dezoito) anos que não concluíram o ensino médio em idade apropriada, inclusive às pessoas privadas de liberdade.

Art. $2^{\circ} \mathrm{O}$ participante do ENEM interessado em obter certificação de conclusão do ensino médio deverá possuir 18 (dezoito) anos completos até a data de realização da primeira prova do ENEM e atender aos seguintes requisitos: I - atingir o mínimo de 450 (quatrocentos e cinquenta) pontos em cada uma das áreas de conhecimento do exame; II - atingir o mínimo de 500 (quinhentos) pontos na redação. (Portaria n ${ }^{\circ}$ 144, de 24 de maio de 2012).

A Portaria no 144/2012 inscreve-se numa posição de democratização do 'acesso' ao Ensino Superior. Observa-se que a posição do Estado, no que enunciam os artigos $1^{\circ}$ e $2^{\circ}$, da referida Portaria, funciona como mediador de uma política "inclusiva" e "expansionista", pois ao certificar alunos maiores de 18 (dezoito) anos, que não concluíram o ensino médio em idade adequada, faz legitimar uma política responsiva. Isto é, o Estado coloca o sujeito-aluno - mesmo com ensino fundamental incompleto - a inverter o jogo sequencial das etapas de escolarização e concorrer a uma vaga no ensino superior. Uma política de certificação que 'fura' com o modelo sequencial do sistema educacional brasileiro.

A possibilidade de certificação nos faz refletir sobre a "falta" do Estado em relação ao ensino. Expliquemo-nos: garantir o certificado a alunos que ainda não concluíram o ensino médio, mas obtiveram pontuação mínima no Exame Nacional (cf. portaria nº 144/2012, item I do art. $2^{\circ}$ ), nos faz pensar no lugar da falha do Estado, que (des) responsabiliza pelo aprendizado do aluno. Observa-se que o artigo $2^{\circ}$ da referida portaria diz que a pontuação 
funciona como condição para que o sujeito-aluno obtenha o certificado de conclusão do ensino médio. Ou seja, não importa a relação aluno/conhecimento, mas aluno/nota. Ao atingir determinada pontuação, o Estado assegura-lhe a conclusão do ensino médio; e isso nos faz pensar na redução do tempo de escolarização e na insuficiência que isso demanda em termos de conhecimento, assim como nos distintos processos de escolarização.

A idade (dezoito anos), expressa nos dois artigos da Portaria $n^{\circ} 144 / 2012$, funciona como condição para o sujeito, que não concluiu o ensino médio em idade apropriada inscrevase no Exame Nacional, mesmo estando ausente da escola por tempo indeterminado. Percebese, assim, o funcionamento de duas formas-sujeito no discurso da Portaria em análise: o sujeito não escolarizado em idade prevista, conforme a lei ${ }^{15}$ e o sujeito privado de liberdade.

A política inclusiva e expansionista produz efeitos de sentido que repercutem na noção de consenso e democracia, o que produz, em certo sentido, a segregação. De acordo com Orlandi (2010, p. 6-7), "quando se pensa o consenso, se pensa a ligação que une a sociedade. [...] a produção do consenso está sustentada em uma concepção de vínculo social que produz a segregação". Para a autora, o consenso traz a noção de unidade. No entanto, ele nunca será absoluto, uma vez que se trata de uma noção que sustenta um processo discursivo que engloba as políticas públicas urbanas.

Ao considerar as condições de produção do discurso em questão (Portaria $\mathrm{n}^{\circ}$ 144/2012), percebe-se que há uma equivocidade no emprego da palavra certificação; na maneira como está inscrita na portaria. É preciso pensar os sentidos do termo certificação como parâmetro, o que faz ressoar a ideia de medidas relativas à avaliação de produtos e serviços. Neste caso, citamos o INMETRO $^{16}$, que certifica um produto em relação à sua qualidade, uso, etc. No caso do ENEM, nos perguntamos: a certificação se refere ao aluno ou ao ensino? Certifica-se este ou aquele? O INEP, ao afirmar que certificará alunos concluintes do ensino médio, legitima-se como órgão regulador da política educacional brasileira. Há sentidos inscritos na palavra certificação que se contrapõem à naturalização de uma política dita "expansionista", que visa a parametrizar e/ou (res) significar a política educacional. Questões que ficam para possíveis reflexões, uma vez que, a própria Análise de Discurso,

\footnotetext{
${ }^{15}$ A conclusão do ensino médio em idade adequada, conforme o $\S 1^{\circ}$ do art. 208 da Constituição Federal e art. $5^{\circ}$ da LDB é de 17 anos de idade.

16 Criado pela Lei 5.966, de 11 de dezembro de 1973, o Instituto Nacional de Metrologia, Qualidade e Tecnologia - Inmetro tem a função de prover confiança à sociedade brasileira nas medições e nos produtos, através da metrologia e da avaliação da conformidade, promovendo a harmonização das relações de consumo, a inovação e a competitividade do País.
} 


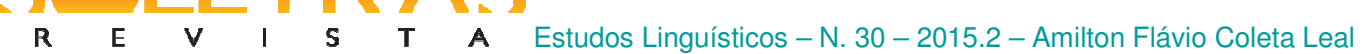

como dissemos, não é uma ciência exata. É uma ciência da interpretação; ela não estaciona em uma interpretação, ela a interroga.

\section{Considerações Finais}

Observou-se, pelo presente trabalho, que há, no ENEM, uma classificação em forma de número, de uma nota a ser recebida de acordo com a competência (ou incompetência) do sujeito-aluno. Isso, a nosso ver, remete a questão de pura quantificação. Simões (2014) diz sobre os sentidos de um discurso quantitativo que atravessam o ENEM. Para a autora, esse discurso visa a apresentação de dados por meio de um instrumento de avaliação que qualifica o sujeito-aluno a partir da nota obtida. Sendo assim, a maneira como se dá a ler as três portarias é:

1- A Portaria $n^{\circ} 438$, que institui o ENEM, apresenta-o como modelo de avaliação a alunos do ensino médio;

2- A Portaria $n^{\mathbf{o}} 109$ funciona como possibilidade de acesso ao ensino superior, a partir de processos seletivos, tais como ProUni, SISU e FIES;

3- A Portaria $\mathrm{n}^{\circ} 144$ visa certificar alunos do ensino médio, maiores de dezoito anos e também aos cidadãos privados de liberdade.

Nosso objetivo foi refletir como tais documentos organizam sentidos numa política de língua. Dessa forma, recortando essa questão para as considerações finais, nos perguntamos: O que muda nas diferentes versões do Exame? Quais deslocamentos ocorrem entre uma portaria e outra? Entendemos, como Orlandi (2012), que qualquer mudança na materialidade do texto corresponde a diferentes gestos de interpretação. Sabe-se que a questão dos sentidos é uma questão que não se fecha, pois a interpretação, tal como formulou Orlandi (Idem, p. 18), "é o vestígio do possível, é o lugar da ideologia materializada na história”. Dessa forma, analisando a reformulação das três portarias, observa-se que há uma repetição nos termos autoavaliação e acesso. Isso nos faz pensar que, onze anos após a instituição do ENEM, permanece a estratégia política de avaliar e (im) possibilitar o acesso ao ensino superior.

O gesto de se autoavaliar faz mover a questão da individuação (Orlandi, 2012), à medida que classifica, seleciona (secciona) os sujeitos conforme a competência na/para a escrita. Neste caso, observa-se que o processo de individuação do sujeito é marcado por aquilo que ele produz de relevante para a sociedade. 
O processo de individuação de que fala Orlandi (2012) se dá pela inscrição do indivíduo (bio-psico) na língua. Este é interpelado em sujeito pela ideologia, constituindo-se numa forma-sujeito. Este processo faz com que, no século XX, o ENEM chegue ao país atravessado pelo discurso de acesso ao ensino superior, legitimando um imaginário de política pública eficiente e democrática. Em outros termos, depreende-se que o sujeito é interpelado, ideologicamente, a romper as engrenagens do político e conseguir o acesso à universidade e ao mercado de trabalho.

A nosso ver, o processo avaliativo do ENEM toma uma engrenagem, uma repercussão; em que se tem a instituição de um programa de avaliação inscrito em uma formação discursiva com o objetivo específico de avaliar o ensino médio e possibilitar o acesso à Universidade. Entretanto, no decorrer das edições, permanecem os objetivos e, amplia-se o acesso ao ensino superior; passando a funcionar, também como possibilidade de certificação do segundo grau. Assim, a (re) escritura das portarias inscreve-se em formações discursivas diversificadas, no entanto com as mesmas proposições para a sociedade. Esse processo faz com que as diferentes posições-sujeito, consequentemente, tomam corpo e se subjetivam nas reformulações das portarias.

\section{Referências bibliográficas:}

ALVES, Paulo Afonso da Cunha. ENEM como política pública de avaliação. $102 \mathrm{f}$. Dissertação (Mestrado em Políticas Públicas e Formação Humana) - Faculdade de Educação, UERJ, Rio de Janeiro, 2009.

BARBOSA, Renilce Miranda Cebalho. O Discurso do ENEM de democratização do acesso ao ensino superior: repetição ou deslocamentos? 108 f. Dissertação (Mestrado em Linguística) - Programa de Pós-Graduação em Linguística, UNEMAT, Cáceres, 2013.

BRASIL. Instituto Nacional de Estudos e Pesquisas Educacionais Anísio Teixeira. A redação no ENEM 2013: guia do participante. Brasília: INEP, MEC, 2013. Disponível em: http://download.inep.gov.br/educacao_basica/enem/guia_participante/2013/guia_de_redacao_ enem_2013.pdf. Acesso em 24 fev. 2014.

Ministério da Educação. Instituto Nacional de Estudos e Pesquisas Educacionais Anísio Teixeira. Enem: Documento Básico. Brasília: MEC/Inep, 2000.

ORLANDI, Eni Pulcinelli. Políticas públicas de ensino. In: Discurso e políticas públicas urbanas: a fabricação do consenso. Campinas, SP: Editora RG, 2010.

Análise de discurso: princípios e procedimentos. 7. ed. Campinas, SP: Pontes, 2008. 


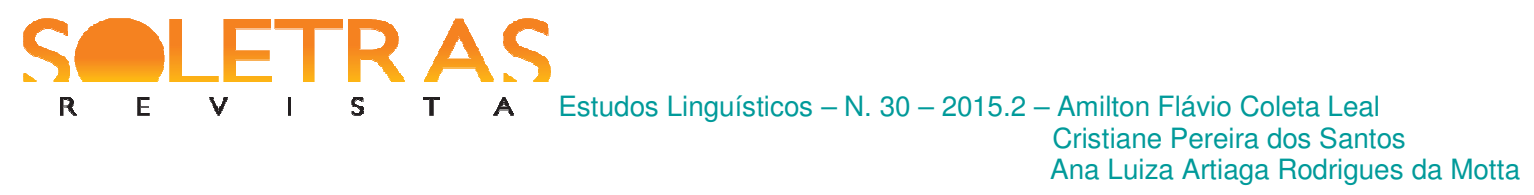

LEAL, Amilton Flávio Coleta. A Formulação da proposta de redação do ENEM: a projeção imaginária do sujeito-escritor ideal. 110f Dissertação (Mestrado em Linguística) - Programa de Pós-Graduação em Linguística, UNEMAT, Cáceres, 2015.

PÊCHEUX, Michel. Sur les contextes épistemoloques de l'analyse de discours. (1975) Trad. Eni P. Orlandi. Sobre os contextos epistemológicos da Análise de Discurso. In: Escritos, n. 4, p.7-16. Campinas. Labeurb; Nudecri, 1999.

O discurso: estrutura ou acontecimento. 4. ed. Campinas, SP: Pontes, 2009.

PFEIFFER, Claudia Regina Castellanos. Políticas Públicas: Educação e Linguagem. In: Cadernos de Estudos Linguísticos. Campinas, SP, 53 (2): 149-155, jul.-dez. 2011.

SANTOS, Jocenilson Ribeiro. A constituição do enunciado nas provas do ENEM e do ENADE: uma análise dos aspectos semiológicos da relação língua-imagem sob a ótica dos estudos do discurso. 169 f. Dissertação (Mestrado em Linguística) - Programa de PósGraduação em Linguística/UFSCar-SP, 2011.

SIMÕES, Stella Maris Rodrigues. A redação no (e do) ENEM: o dizer e o silenciar $105 \mathrm{f}$. Dissertação (Mestrado em Ciências da Linguagem) Universidade do Vale do Sapucaí UNIVÁS - Pouso Alegre, MG, 2014.

\title{
The reformulation of the ordinances of the ENEM: a discursive analysis of the different versions
}

\begin{abstract}
In this paper, the subject language and meaning is studied from the perspective of discourse analysis, based on the work of Pêcheux, France and Eni Orlandi, Brazil. We aimed to reflect the legal process of establishing the ENEM, evaluative policy survey and an analysis of reformulations of the three major ordinances, since it was established in 1998, by 2012 . We highlight the relevance of this study to the mastery of language, especially to researchers who turn to think about educational policies, since the evaluative policy of the National Examination is constituted as the evaluator tool quantifier and the skills of candidates who, in turn, direct the State policies in relation to the school setting. Thus, we say reflect on the national assessment policy ENEM, it made us think of a question very 'face' teaching in Brazil: the subject / writing.
\end{abstract}

Keywords: Discourse Analysis. ENEM. Ordinances.

Recebido em: 02 de setembro de 2015.

Aprovado em: 01 de fevereiro de 2016. 